\title{
Introduction
}

\section{Masahiko Aoki}

This volume is a collection of 22 articles that I have written for professional journals and edited volumes in the past 45 years. Naturally there are variations in theme, focus, approach and style among these writings. The articles are therefore organized into four parts according to basic themes.

Part I: Comparative Mechanism Design includes eight chapters dealing with economic and organizational processes as computation/information systems. Four chapters in section A deal with the design of resource allocation processes for non-neoclassical environments (that is, non-convexity, externalities) in the 'price versus quantity' framework and four chapters in section B analytically compare properties of vertical, horizontal and modular coordination mechanisms in organizations.

Part II: The Diversity of Corporate Governance: A Cooperative Game Approach consists of four chapters that analyze the nature of corporate governance as multiple, equilibrium responses to varied information systems of the corporate firm as discussed in Part I, section B. In this approach, the universal validity of the orthodox shareholders' sovereignty view of corporate governance is challenged. It does not hold as equilibrium for emergent information systems in which the rights of controlling physical assets needs to be complemented by cognitive assets of employees.

Part III: Analysis of the Endogenous Nature of Institutions includes five chapters that provide a conceptual framework for understanding institutions as endogenous outcomes of the societal process in which individual beliefs and strategic actions are mediated by public representations of common knowledge. They provide a game-theoretic foundation for important notions in institutional studies such as institutional complementarities, enforcement, social embeddedness, customs, and path-dependence. By so doing, these chapters suggest an inter-disciplinary approach to institutions that endogenizes institutionalized linkages of economic, political, social, and public domains.

Part IV: Institutions in East Asian Economic Development contains five chapters. They are applications of the methodology presented in Part III for understanding unique institutional forms and processes in East Asia across economies and over time, while providing supporting materials for the methodology as discussed in Part III. These chapters challenge various conventional views that characterize institutions of East Asia simply in terms of exotic culture.

Given this general frame, I briefly introduce below the basic motivation and content of each chapter and its relation to the literature, both at the time of writing as well as now.

\section{Part I Comparative mechanism design}

\section{A Qualityvs.price in non-neoclassical environments}

When I was an undergraduate student of the University of Tokyo around the turn of the 1960s, almost every course in economics was taught in Marxian tradition. However, the practical 
realities of the authoritarian regime of the Communist countries then compelled young students like me to question the validity of the Marxian premise of Historical Materialism: the inevitable replacement of the market economy with the socialist planning. During the days of such soul-searching, I encountered a fascinating article by K.J. Arrow and L. Hurwicz, entitled 'Decentralization and Computation in Resource Allocation' (1960). It was a rigorous mathematical formulation of the Lange-Lerner model of price-based planning and its solution. Solitary reading of this and their other articles urged me to seek the mentorship of Hurwicz at the graduate economics program of the University of Minnesota in 1964.

By then, general equilibrium analysis of the Walrasian price mechanism had been elegantly performed under the neoclassical assumption of the convexity of economic environments (that is, the absence of increasing returns and externalities). In order to proceed a step further, Hurwicz published a highly original paper entitled 'Optimality and Informational Efficiency in Resource Allocation Processes' (1960), in which he proposed to look at the economic mechanism as 'variables' rather than 'a datum'. More specifically he called for exploring the possibility of mechanisms that can deal with 'non-neoclassical environments' with desired properties of Pareto optimality, 'informational efficiency' and 'incentive compatibility': the research program that would eventually earn him a Nobel prize. Thus, my research focus in my graduate years (1964-67) and subsequent years of my early professional career at Stanford (1967-68) and Harvard (1968-72) was directed to mechanism design in that direction. The first four chapters of Part I are selected from that era.

There are traditionally two notions of increasing returns: internal and external. The former is concerned with increasing returns to operational scale accruable to a single production unit, say, the firm. The latter notion that originates with Alfred Marshall deals with the productivityenhancing effects of industrial expansion on individual firms (such as through an improvement of industrial organization due to the division of labor, and accumulation of knowledge). Using a simple one consumer, two industry model, Chapter 1, 'A Note on Marshallian Process Under Increasing Return', shows that the second, external notion of increasing returns is compatible with the existence, optimality, and stability of an equilibrium of competitive price mechanism supplemented by an appropriate ad valorem tax-subsidy system, while the former, internal type requires a quasi-centralized mechanism in which the Central Planning Board (CPB) revises quantity allocation in response to price-like data sent from component units to achieve an optimality. ${ }^{1}$ The first, quasi-Walrasian equilibrium approach to the Marshallian external economies (and diseconomies) is more rigorously formulated and its existence conditions are clarified in Chapter 2, 'Marshallian External Economies and Optimal Tax-Subsidy Structure', with an extension of the standard of general equilibrium approach prevailing then to the case of non-convexity. ${ }^{2}$

The second 'planning' approach is applied to the system composed of multiple production units subject to internal increasing returns to scale in Chapter 4, 'An Investment Planning Process for an Economy with Increasing Returns'. CPB in this model receives the message regarding marginal returns to investment fund allocation from each unit and revises allocation across units by comparing their messages. It may be regarded as an attempt to open the black box of the firm in which the role of CPB is performed by its management (cf., Chapters 3-8 below).

A similar planning idea is applied in Chapter 3, 'Two Planning Processes for an Economy with Production Externalities', to the system in which individual component units mutually 
and directly exercise external economies/diseconomies. Although the word CPB is used, CPB in this model does not centralize all the information regarding production possibilities. The $\mathrm{CPB}$ is used as a metaphor for the mechanism in which quantity allocation (for example, permitted limit of pollutant) to each unit is to be revised (for example, by the regulator) according to price-like information (for example, marginal cost of reducing unit pollutant) dispatched from component units. ${ }^{3}$ Information flows in this mechanism are asymmetrical to those in the Walrasian mechanism in which the auctioneer revises price announcements in response to quantity messages (demands and supplies) dispatched from individual agents. The dimensionality of the message space in this quantity-based mechanism can be regarded as the minimum to achieve the optimality (thus informational efficiency) in the presence of externalities, confirming Hurwicz's earlier conjecture (Hurwicz, 1960).

Although these articles were at the theoretical frontier on the informational-efficiency side of mechanism design at that time (see Hurwicz 1972, 1973), ${ }^{4}$ on the incentive-compatibility side they remained neoclassical. Namely, individual agents were assumed to take information sent from the CPB as parameters in their decentralized computations rather than to strategically manipulate their messages to affect the CPB's response to their private advantages: the major concern of the mechanisms design theory after another seminal paper of Hurwicz (1972).

\section{$B \quad$ Vertical, horizontal and modular coordination}

A seminal paper by Coase (1937) attributed one of the reasons why the firm emerges in the market economy to saving the cost of 'discovering what the relevant prices are' (p.39). Indeed, the firm often enjoys internal increasing returns to scale through the adoption of large scale equipments, the division of labor, collective learning by doing and so on, whereas its operation may be subjected to various externalities internal to the firm such as mutual help and learning among workers, congestion in the use of corporate resources and so on. The firm then emerges as a device to internalize a non-market coordination mechanism by making the corporate management its CPB. Thus the following four chapters depart from the neoclassical view of the firm as a black box or as a mere command system, and instead look at it as a mechanism of information exchange and processing among constituent units. Chapters in this part formulate three alternative mechanisms of industrial coordination within the firm and compare their information efficiency in the Marschak-Radner team-theoretic framework (Chapter 12 discusses under what condition the team approach is relevant even to situations where organizational participants may have different preferences).

Chapter 5, 'Horizontal vs. Vertical Information Structure of the Firm', formulates two mechanisms internal to the firm - horizontal and vertical - and examines their comparative cost advantages depending on parameters such as the magnitudes of stochastic variances of environments, the speed and capacity of learning of agents carrying information processing tasks, the degree of technological complementarities and capacity constraints among component units and so on. This chapter was partially motivated by the debate over the relative competitiveness of Anglo-American firms (acronymed the A-firm) against Japanese firms (acronymed the J-firm) that was raging in the mid-1980s. This theoretical model suggested that the comparative advantages of both types are relative ones, depending on industrial and human capital characteristics and so on. The model foreshadowed the subsequent emergence of the 'horizontal' supply chain across firms in the 1990s replacing the integrated 'vertical' firm. 
If the informational-efficiency advantages of the A-firm and the J-firm are relative, why are those organizational forms sustained as conventions rather than an optimal organizational mix emerging in each country? What will be the consequences of competition between different organizational conventions through free trade and foreign direct investment? Chapter 6, 'The Evolution of Organizational Conventions and Gains from Diversity', constructs an evolutionary game model and shows that non-optimal, information-systemic configurations can evolve across different economies in a path-dependent manner, even if they face the same technological possibility and are mutually engaged in free trade. It also clarifies conditions for the optimal mix to evolve as an equilibrium.

Close observations of the emergence and development of Silicon Valley phenomena around my home institution, Stanford University, led me to model yet another mechanism of industrial coordination: modularity. Chapter 7, 'Information, Incentives and Option Value: The Silicon Valley Model', jointly written with H. Takizawa, formulates its informational-processing and incentive-enhancing properties. ${ }^{5}$ In this model, the innovative design of a potential system starts out with its decomposition into constituent modules and an explicit formulation of interface rules among them. But, the concrete design task of each module is delegated to multiple operational units who compete for better design by encapsulating own information processing from each other. Then, a system is evolutionarily formed by selecting one unit from the many for each module, contingent on their interim performance. This chapter clarifies conditions - the presence of large uncertainty - for the incentive and information advantages of the modular mechanism vis-à-vis the horizontal and vertical mechanisms in spite of initial costs involved in the duplication of modular design tasks.

Three-way comparisons between vertical, horizontal and modular industrial coordination are succinctly summarized and their properties in situations subjected to large shocks are assessed in Chapter 8, 'A Comparative Institutional Analysis of the Fukushima Nuclear Disaster: Lessons and Policy Implications'. It points out that information and incentive properties of each of the three mechanisms may be respectively relevant for understanding the causes and consequences of three major nuclear plant disasters at Chernobyl, Fukushima and Three Mile Island. From this perspective, it derives lessons for preparing and coping with large system shocks. More specifically, it discusses ways to design and regulate the complex structure of the nuclear power industry.

\section{Part II The diversity of corporate governance structure: a cooperative game approach}

Part II contains four chapters that deal with governance of the firm viewed as internalizing non-market coordination. Corresponding to the varieties of coordination mechanisms (information systems) as discussed in Part IB, there can also be a variation of governance structure that stabilizes each organizational variety in an efficient and incentive-compatible manner. These chapters try to clarify this point relying on cooperative game theory. The last chapter discusses why and under what conditions this approach can make sense even if participants of corporate firms may have different preferences. It points to the role of shared norm of fairness: a theme further discussed in Part III.

If workers' contributions to the internal coordination mechanisms are specific to the firm and cannot be valued by markets, the distribution of organizational gains ought to become subjected to internal bargaining among organizational participants. Chapter 9, 'A Model of the 
Firm as a Stockholder-Employee Cooperative Game', attempts to capture this intrinsic internal process as a Nash bargaining game between the holders of financial/physical resources, dubbed the shareholders, and those of firm-specific human resources engaged in the internal coordination mechanism, dubbed the workers (the word 'workers' is used broadly to include managers and engineers, as well as physical workers). Underneath varied institutional forms of corporate governance and human resource management, there is laid a process of distribution. This analysis shows that the bargaining frontier depicting possible combinations between share values for the stockholders and workers' remunerations becomes necessarily non-convex outward. Thus one corner solution provides the neoclassical share value maximization, while the other the worker-controlled firm.

However, more generally, a stable Nash bargaining solution can be achieved by following increased value of the sum of the preferences of the two constituent partners, with their respective risk attitudes (boldness as defined by Aumann and Kurz, 1977) as variable weights along the frontier. Binmore (2005) characterizes the Nash bargaining solution as the only agreement that would emerge in the so-called original position under the Rawlsian veil of ignorance. As such 'it represents the deep structure of the fairness norm that everyone actually uses in daily life'. My approach characterizes the Nash bargaining solution through the formulation of a (fictitious) bargaining process between the risk-averse, rational bargaining partners. A similar process is analyzed by Young (1993) in the context of an evolutionary game. These apparently different approaches to the Nash bargaining solution may be thought of as shedding light on complementary aspects - normative, rational and evolutive - of stable corporate governance as a social compact.

The model is made more specific in Chapter 10, 'Equilibrium Growth of the Hierarchical Firm: Shareholder-Employee Cooperative Game Approach', to capture the situation in which workers have positive time preferences because of their internal career opportunities. In this case, the Nash solution dictates a firm's higher investment rate than the point that generates the maximum share value subject to the current rate of compensation to the workers.

The applications and relevance of the bargaining game model of corporate governance to substantive institutional and organizational issues are discussed in Chapter 11, 'Managerialism Revisited in the Light of Bargaining-Game Theory'. They are further expounded in a subsequent book, The Cooperative Game Theory of the Firm (Aoki, 1984). This book assessed and compared corporate governance practices and legal debates at that time in the UK, US, EC, Germany and Japan. Specifically, it argued that the shareholder-sovereignty orientation prevailing in the US at that time could be regarded as fitting her specific labor market and union institutions in a path-dependent manner. However, as the globalization of financial markets proceeded at unprecedented speed and scale in the late 1980s and 1990s, this model gained a universal prominence as far as leading corporate law scholars proclaimed: "the end of history for corporate law' (Hansmann and Kraakman, 2001). However, regulatory capture by financial interests based on such theory-cum-ideology and their free-handed pursuit of greed had destabilizing impacts on the global corporate economy, leading to financial crisis in 2007.

How is the corporate governance landscape actually evolving because of the globalization of the financial markets? How is it interpreted analytically? Chapter 12, 'A Shapley-Value Parable of Corporations as Evolving Systems of Associational Cognition', attempts to answer these issues by expanding the scope of the cooperative game-theoretic approach. An 
often-raised question to my approach has been 'why the cooperative game?' How can corporate participants, shareholders, managers and workers alike commit to a prior agreement without reneging on it ex post? First, in a manner reminiscent of the information-systemic approach to the firm, the chapter points to the generic nature of the corporate body as a device for associational cognition (group-level, distributed cognition). Indeed, the corporations that historically emerged prior to business corporations were churches and universities created 'for the encouragement and support of religion and learning' (Blackstone, [1765-69] 2005). Of course, the primary purpose of business corporations is not knowledge accumulation and transmission per se. However, shareholders, managers and workers respectively play specific, interactive cognitive roles for business purposes. Then, under what conditions can these agents with different preferences and objectives act in such a joint venture as if they have the same objective function? Theoretically, this question relates to the one raised in Part IB above: can the team approach to organization à la Marschak and Radner (1972) be useful at all for an analysis of organizational behavior?

By applying a proposition in potential game theory due to Monderer and Shapley (1996) and Ui (2009), it can be shown that the corporate participants can act as if they pursue an identical objective if and only if they expect that the value outcome of their associational cognition would be distributed among them according to Shapley value assignments (equivalent to the Nash bargaining solution in the two person game). However, Shapley value assignments could differ, depending on how essential each participant's cognitive capacity is in associational cognition. And their essentiality properties depend on the nature of associational cognition in terms of complementarities of participants' cognitive capacities and their relations to physical assets, as well as the mode of human capital distribution in society. From this perspective Chapter 12 identifies six generic forms of corporate governance reminiscent of classical authoritarian, traditional Anglo-Saxon, German, Japanese, and Silicon Valley models, as well as a new form evolving out of these traditional models in places where both managerial and workers' cognitive assets become mutually essential. This last emergent form is precisely the one that the shareholder sovereignty view cannot capture because of their biased focus on shareholders' controllability of physical assets. See Corporations in Evolving Diversity: Cognition, Governance and Institutions (Aoki, 2010) for a detailed description of this emergent corporate landscape.

If we interpret the Shapley value as representing the fairness norm à la Binmore (2005), the Monderer-Shapley Theorem suggests a significant implication to the topic of Part III as well: the sharing of a fairness norm among organizational participants is a consequence of, as well as a safeguard for, the stable governability of an organizational architecture of associational cognition. In this way, the corporate firm as an organization can act as a coherent player of the game in wider social and economic contexts.

\section{Part III Analysis of the endogenous nature of institutions}

In the 1990s, Paul Milgrom (specialized in market design), Avner Greif (institutional history), Yingyi Qian (transition economics), Marcel Fafchamp (development), John Litvack (transition economics) and myself together ran a graduate field of Comparative Institutional Analysis at the Economics Department of Stanford University. A unified orientation shared among us and students in this field was to conceptualize and analyze varied institutions as endogenous (multiple) equilibrium outcomes of societal games in varied forms and contexts. In contrast, 
preceding New Institutional Economics regarded institutions as exogenously given rules of the game (for example, North, 1990; as 'families of game forms' by Hurwicz, 1996; with a notable exception to the exogenous view being Schotter, 1981).

The advantages of an endogenous (equilibrium) view of institutions are manifold. It can deal with the enforcement of the rules of the game endogenously. It does not need to consider the motivation of the enforcer to enforce the rules that may lead to infinite regression. As a corollary, it does not regard institutions as changeable solely by 'government decree' (North, 1990), unless it is consistent with non-governmental agents' beliefs and strategic choices. Also, varied institutions on different domains - say economic, organizational, social and constitutional - may be seen to form an integrative, robust whole, because an equilibrium approach can analyze their interrelatedness as equilibrium linkages of strategies of agents across those domains.

Chapter 13, 'Towards a Comparative Institutional Analysis: Motivations and Some Tentative Theorizing', delivered as the Presidential Address at the Japanese Economic Association's annual meeting in 1995, provides a statement of basic ideas, motivations and agendas of an equilibrium approach to institutions, which eventually led to the writing of a comprehensive treatise on institutions: Toward a Comparative Institutional Analysis (Aoki, 2001a).

The two following chapters discuss how game-theoretic tools can be drawn on to formally conceptualize and analyze the implications of two basic notions of institutional studies: institutional complementarities and social embeddedness. Chapter 14, 'The Contingent Governance of Teams: Analysis of Institutional Complementarity', conceptualizes a notion of institutional complementarities as equilibria of supermodular games in which agents' payoffs are complementary in their strategies across varied domains of societal games (cf. Milgrom and Roberts, 1990). The chapter then applies this notion and associated analytics to show how the combination of the then unique features of financial and organizational structures in the Japanese economy formed a resilient institutional whole. A notion of institutional complementarity was subsequently proposed by the Varieties of Capitalism School (for example, Hall and Soskice, 2001). However, their notion amounted to ad hoc characterizations of functional interdependencies between the polity and the economy and lacked an explicit treatment of agents' incentives and strategies therein. Such an approach can attribute possible sources of institutional change only to external shocks. In contrast, the supermodular approach traces a possible institutional change as a consequence of agents' cumulative strategic interactions over time as discussed in Chapter 16 below.

Chapter 15, "Individual" Social Capital, "Social" Networks, and their Linkages to Economic Game', discusses another interesting case of strategic approach to institutional phenomena. There are two background notions in the economics and sociological literature that motivate the theme of this chapter: social embeddedness and social capital. In his influential sociological article, Granovetter (1985) (rightly) criticized economists for ignoring the phenomena that agents may refrain from outright selfish behavior in economic transactions that would impair their reputation in social networks. Such considerations can also be strategically formulated and analyzed. The agents may be striking a balance between economic benefits and emotional rewards even in choosing economic actions. Such a view seems to be endorsed by recent theoretical and empirical developments in neuroscience. ${ }^{6}$

The concept of social capital also originates in the writing of the sociologist, Coleman (1994), and has been widely accepted by economists as well. However, Chapter 15 argues that 
the way in which the concept is used among sociologists and economists as something like collective goods may not be appropriate. How is it generated and sustained? Is it tantamount to social customs or norms? If it is capital, is it formed through someone's abstention from today's pleasure for future pleasure? This chapter argues that a way to resolve these issues is to reserve the notion of social capital as individual social assets. Namely, individual agents mutually exchange varied social symbols to affect others' emotions in the expectation of reciprocity. Then such actions in reduced form may be regarded as investment in one's own social capital. As such exchanges may be strategically linked with economic transactions or political choices, certain equilibria may emerge as social norms, customs, or sometimes even as welfare-reducing herd behavior that embeds the latter. This chapter is somewhat polemicoriented, but more analytical expositions of the idea are given in Aoki (2001a, Chapters 2.2, $10.1 ; 2001 b)$.

Chapter 16, 'Endogenizing Institutions and Institutional Change', starts with a succinct summary of theoretical developments of the endogenous view of institutions as initially envisioned in Chapter 13. The chapter restates the ways in which economic, social, political and organizational interactions by agents can be formulated in terms of games and how strategic play across those domains may be interconnected. Then it suggests the ways to understand these linkages in dynamic context so that they can be applied to an analysis of institutional change. A prevailing view of institutional change is to pinpoint the source of institutional change in the polity (for example, North, 1990; North et al., 2009). Acemoglu and Robinson (2012) narrated a grand history of institutions on the premise that the failure of nations to prosper is an inevitable consequence of 'extractive' (as opposed to 'inclusive') political institutions that create private gains for elites, even if by so doing they impoverish the broader constituents of the society. Then, how can bad institutions be reformed? Their stance appears to be rather pessimistic in emphasizing elements of serendipity in institutional change. In contrast, this chapter presents a strategic-analytical perspective in which a momentum for institutional change may occur co-jointly across varied domains including, but not limited to, the political domain through dynamic strategic complementarities and linkages.

Chapter 17, 'Institutions as Cognitive Media Between Strategic Interactions and Individual Beliefs', shares the generic view of institutions in Chapter 16 as 'salient ways of the societal games recursively played and expected to be played'. Both chapters describe the essence of the institutional process that would yield such a recursive state in terms of circular flow diagrams spanned by the individual-versus-society dimension and the cognitive-versus-action dimension (Figure 1 in both Chapters 16 and 17). However, while Chapter 16 regards shared individual beliefs as a crucial element of institution, Chapter 17 is now inclined to take a more externalist stance. Revisiting the original conceptualization of common knowledge by Lewis (1969) and an epistemic game-theoretic analysis of common knowledge by Aumann and Brandenburger (1995), this chapter makes explicit the crucial role of public representations in the institutionalization process that linguistically summarize, and are confirmed by, the recursive states of play and thus induce convergent individual beliefs. These representations can take forms such as enforceable laws, customs, conventions, organizations and even shared ideology as implicit in mythology, parables and the like. I refer to these linguistic external artifacts as the 'substantive forms' of institutions. In this way, my approach may be seen to have come to some terms with the traditional institution-as-the-rules-of-the-game view. However, note that what underlies these substantive forms at the generic level is the 
equilibrating process flowing through cognitive and physical, as well as between collective and individual, phases. Then substantive forms can become external cognitive resources shared by individual agents in society, but they cannot serve as such simply because they are there, decreed by the government, legally enforceable and so on. Rather they have to be either taken for granted, legitimate, enforceable in practice, trustworthy and the like, which is possible only if they mediate an equilibrating process. As such they should be subjected to equilibrium analysis. ${ }^{7}$

\section{Part IV Institutions in East Asian economic development}

Part IV collects five chapters devoted to institutional analyses of East Asian economies and histories. They are applications of the methodology developed in Part III as well as providing concrete materials for theorizing the nature of institutional process in general.

I have spent more than two-thirds of my academic lifetime in the US (at Harvard University and Stanford University) and the rest in Japan (at Kyoto University and the Research Institute of Economy, Trade and Industry). Thus, I have been observing my native country from the outside as well as experiencing it from the inside to gain insights into the nature of her institutions in a comparative perspective - sort of à la Tocqueville. Also, since youth, China was a major object of my intellectual curiosity. By the 1970s, I became convinced of the need to familiarize myself not only with the political economy of the West but also that of China. I felt so in order to gain a deeper understanding of the nature, evolution and workings of institutions in a broader and longer perspective, although I did not agree with Joan Robinson (1975) who had a fascination with China's economic management under the Cultural Revolution. In the last days of Mao's rule (March 1976) I had an opportunity to visit Chinese villages, together with a small group of farmers and young economists from Japan, and had a glimpse of what would become the initial conditions for China's subsequent spectacular economic growth. In the 1990s, I had a number of occasions to discuss issues of economic reforms in China with government officials and scholars in my capacity as a consultant for the World Bank and the Chinese Ministry of Finance (Wu 2012). These personal experiences in the US, Japan and China are undoubtedly the basis of my comparative approach to East Asian institutions.

Chapter 18, 'Toward an Economic Model of the Japanese Firm', presents a stylized model of the Japanese firm in its heyday (the 1970s and 1980s), and has been widely referred to in the literature. It described various unique aspects of the J-firm: long-term employment and personnel management, shop floor practices, horizontal coordination inside and across firms, bank financing and its governance role and so on; which formed together a coherent system. Although a notion of institutional complementarities had not yet been clearly spelled out in analytical terms at that time, the description provided empirical support for its subsequent formulation in Chapter $15 .{ }^{8}$ Some aspects of the J-firm, for example its corporate finance and governance aspects, have been substantially transformed since then in response to the globalization of financial markets. Yet other aspects, for example personnel management, are still retained even by competitive corporate giants, which has led to an increasing diversity of the corporate landscape of the Japanese economy (Aoki, 2010, Chapter 5).

During the 1990s I had opportunities to organize four projects related to East Asia and/or transition economies and edit their outcomes for the World Bank Institute, in which 61 scholars and practitioners from 12 countries participated (Aoki and Patrick, 1994; Aoki, 1995; Aoki et 
al., 1997; Aoki and Hayami, 2001). The following three chapters are drawn from those projects. Chapter 19, 'Monitoring Characteristics of the Main Bank System: An Analytical and Developmental View', deals with the monitoring and governance roles of the Japanese main bank system vis-à-vis the J-firm in a non-technical manner. The main bank in its heyday (the 1950s to the early 1980s) integrated ex ante monitoring (that is, evaluation of the J-firm's investment proposal in the broader industrial-policy context), interim monitoring and contingent governance based on ex post monitoring (that is, choice between bailing-out of financially distressed firms versus their punishment through management-takeover or liquidation, contingent on the main bank's evaluation of J-firms' expected continuation value). As a World Bank-sponsored project (Aoki and Patrick, 1994), the chapter aims to derive general, comparative implications of the relational-banking system for developing and transition economies as opposed to the market-oriented financial system in developed economies. However, it also suggests that the value of relational banking will decline as corporate firms grow and become financially viable in competitive global bond markets. If the financial regulator becomes captured by major banks that seek rents even at this stage, the financial and real performance of the economy will eventually stagnate and face a crisis. Based on empirical data provided by Jackson and Miyajima (2007), Chapter 5 of Aoki (2010) discusses how and why the Japanese system has transitioned to one that embraces a significant diversity in corporate governance and financing across firms.

Chapter 20, 'Controlling Insider Control: Issues of Corporate Governance in Transitional Economies', observes that 'market-oriented' privatizations in Central and Eastern economies actually lead to insider control of ex-state-owned enterprises by their managers (and workers) free from outside monitoring, and argued for the importance of co-development of a sound banking system in the transition stage, together with market-based financial institutions - a position not necessarily popular among economists in the mid-1990s. This article was read at the Jinglun Conference in Beijing in 1994 that would have significant impacts on subsequent economic reforms in banking and corporate law in China under the leadership of the then Premier Zhu Rongji (Wu 2005; Wu and Zhou, 1999).

Chapter 21, 'Beyond The East Asian Miracle: Introducing the Market Enhancing View', is from the introductory chapter of Aoki et al. (1997). This chapter challenges two opposing views about the role of government that had been prevalent in the development economic literature at the time: the market-friendly view (taken by the World Bank) that limits the role of government only to meeting the outright absence of markets, on one hand, and the developmental state view that regards direct and broader government intervention in markets as essential in the developmental stage, on the other. The chapter starts from the premise that private sector institutions have important comparative advantages vis-à-vis the government, but from the readings of successful East Asian development experiences in Japan, South Korea and Taiwan, it also argued for the importance of a government policy in facilitating and complementing private-sector coordination in the early development stage.

Chapter 22, 'Historical Sources of Institutional Trajectories in Economic Development: China, Japan and Korea Compared' (2013), goes further back to the pre-modern development stage of the East Asian economies. Recent unified approaches to economic growth (for example, Hansen and Prescott, 2002; Galor, 2011) aim at analyzing transition from the socalled Malthusian stage of growth to the human capital-based modern economic growth regime in a unified framework. In this view, different levels of per capita income are seen as 
different phases of the same growth path. Then, why are there differences in the timing of onset and the duration of the transition from the Malthusian stage to the modern growth regime between the West and the East, as well as within the East? A readily available answer could be 'institutions matter'. But then, will institutional arrangements converge, and ought they to converge, as gaps in economic growth across economies close? Instead of making such conjecture as a premise, this chapter looks back at how political and social institutions in the Qing China, the Tokugawa Japan, and the Yi Korea were respectively arranged in the support of their otherwise similar, peasant family-based economies. Their political states, evolving as stable states of political game complementary to the economic structure, may not be lumped together simply as 'extractive' systems (Acemoglu and Robinson, 2012), for such broad characterization does not seem to be helpful for differentiating the patterns of institutional evolution then and afterwards among the East Asian economies and in contrast to the West. ${ }^{9}$

Historical arguments in this chapter are not based on an original research of primary documents but an institutionalist's interpretations of secondary materials from diverse academic fields. There may thus be too bold statements, and even too liberal interpretations of other scholars' findings. In any case, my stance is not to follow the culturalist approach in the sense that apparently unique cognitive orientation, economic behavior, institutional forms and the like in East Asia are not to be taken as expressions of fixed 'culture-rooted preferences', but as outcomes of context-contingent strategic interactions of agents. As strategic interactions are mediated by linguistic public representations of common knowledge as discussed in Chapter 18, institutional evolution might appear as if it were 'culturally determined'. However, the analysis in Chapter 22 hopefully indicates that it is the strategic interactions of agents in economic, political and social domains of games that are the driving forces of institutional evolution, although they may be 'culturally-intermediated' in the sense just specified.

\section{Notes}

1. The first quasi-price mechanism was suggested by Chipman (1965), while the latter quantity-based adjustment mechanism was previously formulated and analyzed for the linear technological environment by Kornai and Liptak (1965).

2. One specific contribution of this paper to the literature of general equilibrium analysis was to identify conditions that guarantee the boundedness and closedness of the production possibility frontier in the presence of increasing returns to scale so that a fixed-point theorem is applicable. To simplify analysis, on the demand side, a single representative consumer is assumed. However, this assumption can be easily relaxed by using an ingenious method developed by Negishi (1960).

3. Aoki (1970), Chapter VI, discussed the comparative merits/demerits of emission tax and quantity regulation for controlling pollution in the price-versus-quantity framework. It was an early economic contribution to the increasing environmental problem at the time of high growth in Japan.

4. Between 1971 and 1972 I taught a graduate course on Decentralization and Organization at Harvard University together with Hurwicz. Chapter 3 was an outcome of the course.

5. Analysis and discussions of modular coordination in this chapter are preceded by Baldwin and Clark (2000) and Aoki (2000; 2001a, Chapter 10).

6. Recent neuroscientific research reports that there are trade-offs between emotional payoffs and materialistic/ hedonistic payoffs, as if 'neurocurrency' (Montague and Berns, 2002) is being circulated in the network of neurons within an individual's brain (see Fehr and Camerer, 2007; Izuma et al., 2008).

7. Herrmann-Pillath (2013) expands the framework of my 2-by-2 flow chart (Figure 1 in Chapters 16 and 17) in such a way to join one chart representing the 'sign system' with another representing markets and organizations, and analyzes how 'public representations/signs' and agents' behavioral dispositions in the latter can be generated in conjunction. This is a highly promising approach integrating a game-theoretic view of the society with the concept of 'performativity' borrowed from the philosophy of language. The performativity refers to 'speech acts' that creates social facts in the sense of a mind-to-world direction of fit: the direction lacking in the traditional, exogenous view of institutions. 
8. A more detailed analysis of the J-firm in a book form is Information, Incentives and Bargaining in the Japanese Economy (Aoki, 1988).

9. A more expanded historical argument that covers up to the present time is found in Aoki (2012), Chapter 1.

\section{References}

Acemoglu, D. and J.A. Robinson (2012), Why Nations Fail: The Origins of Power, Prosperity, and Poverty, New York: Crown Business.

Aoki, M. (1970), The Economic Theory of Organization and Planning (Soshiki to Keikaku no Keizairiron), in Japanese, Tokyo: Iwanami Shoten.

Aoki, M. (1984), The Cooperative Game Theory of the Firm, Oxford: Clarendon Press.

Aoki, M. (1988), Information, Incentives, and Bargaining in the Japanese Economy, Cambridge, UK and New York: Cambridge University Press.

Aoki, M. (ed.) (1995), Corporate Governance in Transitional Economies: Insider Control and Roles of Banks, Washington, DC: World Bank Institute.

Aoki, M. (2000), 'Information and Governance in the Silicon Valley Model', in X. Vives (ed.), Corporate Governance: Theoretical and Empirical Perspectives, Cambridge, UK: Cambridge University Press, pp. 169-95.

Aoki, M. (2001a), Toward A Comparative Institutional Analysis, Cambridge, MA: MIT Press.

Aoki, M. (2001b), 'Community Norms and Embeddedness', in M. Aoki and Y. Hayami (2001), pp. 97-125.

Aoki, M. (2010), Corporations in Evolving Diversity: Cognition, Governance, and Institutions, Oxford: Oxford University Press.

Aoki, M. and Y. Hayami (eds) (2001), Communities and Markets in Economic Development, Oxford: Oxford University Press.

Aoki, M. and H. Patrick (eds) (1994), The Japanese Main Bank System and its Relevancy for Developing and Transforming Economies, Oxford: Oxford University Press.

Aoki, M., H. Kim and M. Okuno-Fujiwara (1997), The Role of Government in East Asian Economic Development: Comparative Institutional Analysis, Oxford: Oxford University Press.

Aoki, M., T. Kuran and G. Roland (eds) (2012), Institutions and Comparative Economic Development, IEA Conference Volume No. 150-I, Basingstoke: Palgrave Macmillan.

Arrow, K.J. and L. Hurwicz (1960), 'Decentralization and Computation in Economic Allocation', in R.F. Pfrouts (ed.), Essays in Economics and Econometrics, Chapel Hill: University of North Carolina Press, pp. 34-104.

Aumann, R. and M. Kurz (1977), 'Power and Taxes', Econometrica, 45, 1137-60.

Aumann, R. and A. Brandenburger (1995), 'Epistemic Condition for Nash Equilibrium', Econometrica, 63, $1236-40$.

Baldwin, C.Y. and K. Clark (2000), Design Rules: The Power of Modularity, Cambridge, MA: MIT Press.

Binmore, K. (2005), Natural Justice, Oxford: Oxford University Press.

Blackstone, W. ([1765-69] 2005), Commentaries on the Laws of England, at LawMart.com.

Chipman, J.S. (1965), 'A Survey of the Theory of International Trade, Part II', Econometrica, 33, 685-760.

Coase, R. (1937), 'The Nature of the Firm', Economica, 4, 386-405.

Coleman, J. (1994), Foundations of Social Theory, Cambridge, MA: Harvard University Press.

Fehr, E. and C.F. Camerer (2007), 'Social Neuroeconomics: The Neural Circuitry of Social Preferences', Trends in Cognitive Sciences, 11, 419-27.

Galor, O. (2011), Unified Growth Theory, Princeton, NJ: Princeton University Press.

Granovetter, M. (1985), 'Economic Action and Social Structure: The Problem of Embededdness', American Journal of Sociology, 35, 3-11.

Hall, P.A. and D. Soskice (2001), 'An Introduction to Varieties of Capitalism', in P.A. Hall and D. Soskice (eds), Varieties of Capitalisms: The Institutional Foundations of Comparative Advantage, Oxford: Oxford University Press, pp. 1-68.

Hansen, G.D. and E. Prescott (2002), 'Malthus to Solow', American Economic Review, 92, 1205-17.

Hansmann, H. and R. Kraakman (2001), 'The End of History for Corporate Law', Georgia Law Journal, 89, 439.

Herrmann-Pillath, C. (2013), 'Performativity of Economic Systems: Approach and Implications for Taxonomy', Journal of Economic Methodology, forthcoming.

Hurwicz, L. (1960), 'Optimality and Informational Efficiency in Resource Allocation Processes', in K.J. Arrow, S. Karlin and P. Suppes (eds), Mathematical Methods in the Social Sciences, 1959, Stanford: Stanford University Press, pp. 27-40.

Hurwicz, L. (1972), 'On Informationally Decentralized Systems', in C.B. McGuire and R. Radner (eds), Decision and Organization, Amsterdam: North Holland, pp. 297-336.

Hurwicz, L. (1973), 'The Design of Resource Allocation Mechanisms', American Economic Review, 63, Papers and Proceedings, 27-46.

Hurwicz, L. (1996), 'Institutions as Families of Game Forms', Japanese Economic Review, 47, 13-32. 
Izuma, K., D.N. Saito and N. Sadato (2008), 'Processing of Social and Monetary Rewards in the Human Striatum', Neuron, 58, 284-94.

Jackson, G. and H. Miyajima (2007), 'Introduction: The Diversity and Change of Corporate Governance in Japan', in M. Aoki, G. Jackson and H. Miyajima (eds), Corporate Governance in Japan: Institutional Change and Organizational Diversity, Oxford: Oxford University Press, pp. 1-47.

Kornal, J. and T. Liptak (1965), ‘Two Level Planning', Econometrica, 33, 141-69.

Lewis, D. (1969), Conventions, Cambridge MA: Harvard University Press.

Marschak, J. and R. Radner (1972), The Theory of Teams, New Haven, CT: Yale University Press.

Milgrom, P. and J. Roberts (1990), 'Rationalizability, Learning, and Equilibrium in Games with Strategic Complementarities', Econometrica, 59, 1255-77.

Monderer, D. and L.S. Shapley (1996), 'Potential Games', Games and Economic Behavior, 14, 124-43.

Montague, P.R. and G.S. Berns (2002), 'Neural Economics and the Biological Substrates of Evaluation', Neuron, 36 (2), 265-84.

Negishi, T. (1960), 'Welfare Economics and Existence of an Equilibrium for a Competitive Economy', Metroeconomica, 12, 92-7.

North, D.C. (1990), Institutions, Institutional Change and Economic Performance, Cambridge UK and NY: Cambridge University Press.

North, D.C., J.J. Willis and B.R. Weingast (2009), Violence and Social Orders: A Conceptual Framework for Interpreting Recorded Human History, Cambridge UK and NY: Cambridge University Press.

Robinson, J. (1975), Economic Management in China, London: Anglo-Chinese Educational Institute.

Schotter, A. (1981), The Economic Theory of Social Institutions, Cambridge: Cambridge University Press.

Ui, T. (2009), 'Bayesian Potentials and Information Structures: Team Decision Process Revisited', International Journal of Economic Theory, 5, 271-91.

$\mathrm{Wu}, \mathrm{J}$. (2005), Understanding and Interpreting Chinese Economic Reform, Mason, OH: Thomson.

Wu, J. (2012), 'Economics and China's Economic Rise', in M. Aoki and J. Wu (eds), The Chinese Economy: A New Transition, IEA Conference Volume No. 150-I, Basingstoke: Palgrave Macmillan, Chapter 1, pp. 13-31.

Wu, J. and X. Zhou (1999), Corporate Governance Structure, Debt Restructuring and Bankruptcy Procedure: Revisiting 1994 Jinglun Conference (in Chinese), Beijing: Central Compilation \& Translation Press.

Young, P. (1993), 'An Evolutionary Model of Bargaining', Journal of Economic Theory, 59, 145-68. 
Masahiko Aoki - 9781783476213 